Session: 2541

\title{
A Successful Collaborative Partnership Among the Faculty and Librarians at Drexel University with the IEEE
}

\author{
Jay Bhatt ${ }^{1}$, Andrew Wheeler ${ }^{1}$ \& Ruth Wolfish ${ }^{2}$ \\ Drexel University Libraries ${ }^{1} /$ IEEE $^{2}$
}

\begin{abstract}
This paper details a successful collaborative partnership among the faculty and librarians at Drexel University with the IEEE. The primary groups involved in the partnership were the IEEE liaisons and leaders, the Electrical and Computer Engineering (ECE) Department of the Drexel University College of Engineering, the Drexel University Libraries, the Drexel Student Branch of IEEE, and IEEE personnel. This innovative collaborative relationship was based on the IEEE University Partnership Program (UPP). From 2000 to 2004, unique activities and events were held to attract new students to the IEEE and encourage students to use IEEE Xplore, a premier electronic resource providing full-text access to IEEE transactions, journals, magazines and conference proceedings. Additional benefits of these events and activities included: improved information awareness and information literacy among the event participants, improved teamwork and communication skills in the members of the Drexel IEEE Student Branch who had to plan, promote, coordinate, and moderate events for students from Drexel and surrounding institutions, and partial rebates to the library for their subscription to the IEEE information product (contingent on predetermined IEEE Student Branch membership goals).
\end{abstract}

\section{The IEEE}

IEEE (The Institute of Electrical and Electronics Engineers) was formed in 1963. The IEEE has more than 365,000 members in over 150 countries. Of that total, approximately 68,000 are students. The IEEE is recognized as the preeminent international body for electrical engineering and organizes over 350 conferences each year worldwide. The IEEE is also very active in telecommunications, information technology, nanotechnology, robotics and biomedical engineering and has 39 technical societies and publishes over 100 periodical titles.

The IEEE has long encouraged and supported students who are studying electrical engineering and related fields. One example of their commitment to perpetuating their field is the IEEE University Partnership Program - an innovative program that thrives on faculty, student, librarian, and IEEE personnel participation. In the year 2000, Drexel University in Philadelphia, became one of the earliest participants in the IEEE University Partnership Program (UPP). ${ }^{1}$

\section{Drexel University Engineering Curriculum}


The partnership between Drexel University and the IEEE formed for several reasons. Drexel had an established reputation for aggressively pursuing curriculum improvements. In 1989, Professors Eli Fromm and Robert Quinn won a five-year, \$2 million National Science Foundation grant to "enhance the educational experience of engineering students". ${ }^{2}$ The project, referred to as E4 (the Enhanced Educational Experience for Engineering students), was driven by the belief that there needed to be a radical update of the engineering curriculum. ${ }^{2}$

The curriculum improvements pioneered in E4 were carried over into the Drexel Engineering Curriculum (tDEC), established in 1994. ${ }^{3}$ tDEC continues to be used at Drexel for all engineering undergraduate students, and in 1999 further modifications were made to the Electrical and Computer Engineering (ECE) curriculum - this effort was referred to as ECE21. ${ }^{3}$

Industry advances lead to curriculum changes which often increase the time commitment and burden placed on undergraduate engineering students. Cellular telephony, voice over IP (VoIP), nanotechnology, super-conductivity, wireless networks, global positioning systems, and software chip design and manufacture are all critical technologies with strong connections to electrical engineering. If an engineering curriculum focuses on specialty areas over fundamentals, engineers may not be flexible enough to meet new but unforeseen challenges. While several other articles address engineering curriculums, $2,3,4,5,6,7$ it is essential to remember that there is an additional demand on students' time - the ability to find and evaluate information. Information literacy is crucial to students' academic success and long term effectiveness in their chosen fields.

\section{Drexel University Libraries}

In a recent article, Dr. Carol Montgomery notes that from 1998 to 2003 Drexel University's access to electronic journals grew from approximately 2,000 to 12,000 titles. $^{8}$ Some of this expansion was in part due to a merger of library collections when Drexel acquired an independent health sciences university in 2002, but the major factor behind the growth in electronic journal subscriptions at Drexel was the Library's decision to quickly change from a print serials collection paradigm to a nearly all electronic journals collection. This decision, based on economic factors and the resource access preferences of faculty and students, is described in greater detail in previous publications by Dr. Montgomery.

The rapid migration to electronic journals brought many challenges, including a need to promote resources to students and faculty and inform them about content and search capabilities. Seeking, finding, and evaluating information are components of information literacy. Students need to develop strong information literacy skills to take full advantage of the resources and hone their ability to continue learning after they graduate. ${ }^{10}$

Essentially, the libraries had several simultaneous challenges: a new journal subscription paradigm (electronic subscriptions), an overall increase in the number of journal titles to manage, educating users about the different search environments, and fostering information literacy skills in students. The IEEE University Partnership Program helped the library meet some of these challenges while also serving the interests of the IEEE, the students, and the faculty. 


\section{The IEEE University Partnership Program}

Faculty, librarians, and professional societies need to work together to ensure engineering students emerge from colleges and universities with the skills to meet the engineering challenges of the future. While this statement may be true at anytime in history, expanding competitive global markets and an over-abundance of information resources forces people to make quick decisions while simultaneously taking a more active role and spending more time in finding and evaluating information.

Facing a need to reinforce industry perspectives in academic curriculums, improve student information literacy, to promote knowledge of the best information resources, and to improve the odds of students graduating and quickly making a positive impact in their chosen fields, the IEEE launched the IEEE University Partnership Program in May 2000. The goals of the University Partnership Program include increasing the number of members in the IEEE Student Branch and exposing students to IEEE events, conferences, and other resources.

Drexel University was one of the pilot universities in the program. Drexel's motivated faculty, prestigious engineering program, aggressive early adoption of electronic resources, and historically strong support of the IEEE made it an ideal pilot university. Several people contributed to launching the IEEE University Partnership Program at Drexel, and three people in particular provided unsurpassed support and enthusiasm:

- Dr. Bruce Eisenstein - past IEEE President and Arthur J. Rowland

Professor of Electrical and Computer Engineering at Drexel

- Dr. Carol Montgomery - Dean of Drexel University Libraries

- Jay Bhatt - Engineering Librarian

Drexel (as did all participating schools) agreed to specific terms and conditions of the University Partnership Program. These goals included working to meet or exceed an annual student membership growth goal. In addition, participating schools must subscribe to the IEEE/IEE Electronic Library (IEL). Typical IEL subscriptions permitted a limited number of simultaneous users with additional fees for more simultaneous users, but the University Partnership Program participants enjoyed unlimited simultaneous user logins (using IP authentication) and access to the backfile (also referred to as an electronic archive) at no additional charge. Lastly, the program provides free registration, at any IEEE conference, for two students and two faculty members at each participating school, in addition to receiving extra support to promote IEEE and its community on campus. If the agreed-upon student membership goal was met at the end of the year, Drexel would receive a $10 \%$ rebate on the subscription price of the IEEE online information product. ${ }^{1}$

\section{Events}

Events hosted by the participating universities to promote the IEEE to their students are the key feature of the IEEE University Partnership Program. The events were important for several reasons. Both members and non-members of IEEE could interact with faculty and professionals who donated their time to attend the events. IEEE Student Branch members, 
meanwhile, had to develop and use their leadership and organizational skills to plan the events picking a date, time and location, organizing refreshments, booking guest speakers, publicizing the events, etcetera.

IEEE provided their Customer Relations Manager with an event budget. She identified possible speakers that would motivate students to attend these events, and discussed these ideas with the IEEE Student Branch and the Drexel Engineering Librarian before coordinating the events. Once approved, planning and scheduling of events began. The goals of these programs were to make them informative for students, to educate and connect them to the valuable electronic resources available through the library, to provide professional networking opportunities, and finally, to impress upon them the value of joining a professional society, in this case, IEEE.

For the events, IEEE provided customized tip sheets with the Drexel web site information with instructions on using IEEE Xplore efficiently. These tip sheets were provided to all event attendees, and any remaining tip sheets were placed at the reference desk in the library for distribution to students.

IEEE Xplore was the major electronic resource promoted during the events but other resources were also mentioned during an informational overview of the Library web site. This enabled students to become more familiar with the vast array of resources available to them for their research.

Below is a brief description of the major IEEE events hosted at Drexel University:

July 30, 2002: This information/membership event was held in the early afternoon at W.W. Hagerty Library. Attendees enjoyed free refreshments, and students who joined IEEE that day received a free tee shirt. Dr. Moshe Kam, the IEEE Student Branch Counselor, gave a presentation about the IEEE and the Student Branch, and Jay Bhatt, the Drexel Engineering Librarian, spoke about IEEE Xplore, the IEEE online resource.

November 8, 2002: IEEE sponsored a special lecture by Martin I. Finston, Patent Attorney with Lucent Technologies Incorporated. Mr. Finston delivered his presentation three times on November 8 to reach as many Drexel Freshmen Engineering students as possible. The total number of students who attended this event was 688. At each session, the Engineering Librarian introduced the topic of patent research and briefly demonstrated using library subject guides and resources to conduct patent research. After each session the librarian also collected evaluations from the attendees which he later collated for the IEEE. The skills in this session were especially relevant to freshmen engineering students because they are required to gather and present patent information as part of their freshmen engineering design project at Drexel.

May 27, 2003: This information/membership event was held in the early afternoon at W.W. Hagerty Library. Attendees enjoyed free refreshments, and students who joined IEEE that day received a free tee shirt. Dr. Moshe Kam, the IEEE Student Branch Counselor, gave a presentation about the IEEE and the Student Branch, and Jay Bhatt, the Drexel Engineering Librarian, spoke about IEEE Xplore, the IEEE online resource. This involved a 'Tips and Tricks 
session' on using IEEE Xplore to find faculty or companies that are doing similar research in order to help students apply for graduate programs in those universities where research in their areas of interest is being conducted or help students identify prospective companies where they could seek potential employment.

October 9, 2003: In this career path and networking event, students had an opportunity to learn valuable insights for success in professional and corporate environments. The event consisted of a five member panel presenting prepared remarks and taking questions. Panel members also joined the IEEE Student Chapter for dinner after the event. The primary speaker of the evening was Mr. Christopher Deephouse, Drexel alumnus and Director and Principal Architect, GSI Commerce, Incorporated. The four other panel members were also from GSI. and their job titles were: Associate Data Warehouse Engineer, EDI Analyst, Director of Web Technologies and Director of Database Management. Two of the panel members were Drexel alumni, and we appreciate the support of our alumni and their commitment to future engineers. The event also featured a unique prize drawing - in order to qualify for a chance to win a Palm m515, students had to find a citation in IEEE Xplore of an article written by the evening's guest speaker, Mr. Deephouse. The students had to print the citation and bring it with them to the event.

April 27, 2004: This event, held in the evening, was a departure from our earlier membership events. The event featured special guest lecturer David Hamer, visiting research scholar at Bletchley Park Trust (custodians of the cryptographic museum at Bletchley Park in the UK). Mr. Hamer brought an Enigma cryptographic machine with him and gave an excellent talk about cryptography in World War II. The Math Forum@Drexel's website http://mathforum.org/library/topics/cryptography/ provides several informative web sites on Cryptography. These include a web site on Bletchley Park http://www.bletchleypark.org.uk/ and a web site by David Hamer http://www.eclipse.net/ dhamer/aspects.htm .

This event was again held in W.W. Hagerty Library and scheduled so that students from the Cryptography class could attend the event immediately after their class was over. As a result, approximately 75 students attended this event. Attendees also included Dr. Bruce Eisenstein, former IEEE President, and Christopher Deephouse, Software and Data Architecture Chief from GSI Commerce, as well as library staff, university students, and IEEE personnel. The fact that Mr. Deephouse, a speaker from a previous event, attended this event illustrates the continued partnership between Drexel and GSI Commerce, Incorporated.

For this event, Drexel and the IEEE gave away an MP3 player in a special lottery drawing. In order to qualify for a chance to win the MP3 player, attendees had to bring a citation from IEEE Xplore of an article related to the Enigma Machine. This event was also described in detail in the W.W. Hagerty Library Newsletter, Volume 5, Number 3, May, 2004. The following link will connect you to the article, titled "Drexel University IEEE Branch Hosts Talk on Enigma Machine". http://www.library.drexel.edu/news/0403/ieee.html .

\section{Benefits}

IEEE events are viewed as important outreach tools that provided ample opportunities for students, IEEE staff, and librarians to interact and collaborate with each other. These events 
were organized by the IEEE Student Branch with encouragement and support by the library. The IEEE provided event flyers, encouragement and ideas, helped coordinate and promote the events, and helped cover expenses.

These events reinforced vital skills in students - leadership, teamwork, planning, and promoting the exchange of ideas with people outside the classroom setting. For example, during the Oct. 9, 2003 event featuring Christopher Deephouse and other GSI Commerce Inc. personnel, students had an opportunity to learn directly from an experienced group of professionals about professional networking and other career skills. GSI is a leading outsourcing provider for internet retailers, and their personnel gave advice to over seventy-five students about post-graduation challenges and potential career paths. The group of five presenters, two of whom are Drexel alumni, provided tips for succeeding in today's job market and mentioned specific credentials and skill sets that technology companies would prefer to see in college graduates who are seeking employment. The event was followed by a dinner, which provided an opportunity for IEEE Student Branch members and GSI Commerce panelists to discuss a possible future collaborative partnership in entrepreneurship-related design projects.

Each event highlighted particular topics and provided useful information to the students for their future careers. One example was the discussion on patent information provided by the Lucent patent attorney. His presentation taught students how to obtain patents for their inventions and emphasized the importance of retaining the rights to the patents. Student comments indicated an overwhelming appreciation for this event.

Select comments by students about the patents event:

"The Hagerty Library information (is important) because we will need to use it to do research for our products"

"Helped us on how to fill out an application for patent. Gave us lots of insight about what to do if someone tries to steal your patentable idea."

"The most valuable part of today's meeting was talking about infringements because now that we know exactly what it is, we will not get into serious trouble by infringing off of someone's invention."

"Personally think the Drexel links were the most valuable because they allow you to research patents on your own."

Drexel's engineering curriculum includes courses and exercises to emphasize the ethical obligations of engineers. ${ }^{11}$ The focus of the patent discussion was not ethics pre se, but ethicsrelated concepts and relevant research skills were introduced during the event. The comment on 'infringements' clearly indicates the student gained insight into the ethical aspects involved with any invention. The presentation about patents also emphasized acceptable ethical behavior which has always been a critical component both in industry and in academics. 
The events exposed students to other electronic databases besides IEEE Xplore. In order to reach IEEE Xplore, students had to navigate the library website and observe other database links. During the patent event students observed real world uses for the U.S. patent database and they were introduced to online subject guides. Librarians routinely create and maintain online subject guides to help students select and use databases effectively. An example of these subject guides is the "Patent and Patent Searching" guide which can be accessed at http://www.library.drexel.edu/resources/guides/patents.html.

The patent law event was particularly helpful to freshman engineering students, who had to apply the skills and use the resources described during the patent event in partial fulfillment of their mandatory freshmen engineering design projects.

The events also allowed students to relate what they were learning in their classes to practical applications in real life situations. The event on the Enigma Machine gave students a chance to mingle and ask the speaker questions about codes, computer security, and cryptography - subject areas intertwined with their course curriculum.

Most importantly, these events required collaborative efforts involving the IEEE Student Branch members, engineering students, faculty, and the IEEE staff. IEEE Student Branch members successfully worked together as a team to ensure proper event planning (room and equipment reservations, setting up equipment, arranging the seating in the seminar room, arranging for food and refreshments, etc.). Many of these tasks required attention to detail and a coordinated effort well in advance of the event.

The IEEE benefited directly from new members. In the year 2000, Drexel doubled the size of the Student Branch and earned the IEEE Regional Activities Board Student Branch Growth award for this area of the country. In 2002, Drexel's membership goal of 263 was exceeded by 19. Beyond the new members, the IEEE also benefited by ensuring the engineers of tomorrow are ready to take on challenges and add to the legacy of invention and advancement that engineers have contributed to the world.

\section{Conclusion}

In May 2000, Drexel University was selected by the IEEE as one of the initial nine schools to participate in the IEEE University Partnership Program pilot. The IEEE University Partnership Program emphasized the importance of finding and using reliable information and reduced the cost of select electronic resources for libraries. The program also increased membership in the IEEE and provided students with an opportunity to hone their teamwork and leadership skills while interacting with professionals. The program has been a success due in large part to the active support of Drexel faculty and library personnel, IEEE personnel, and Drexel students. A major component of the program was a series of events organized by the Drexel University Student Branch of the IEEE, with help from Drexel librarians and support and financial assistance from the IEEE. We recommended conducting the patent attorney lecture event each year, especially for freshmen engineering students. 
Drexel continues to participate in the IEEE University Partnership Program. Hopefully other professional societies will follow IEEE's example and join with librarians, faculty, and students to improve the students' awareness of professional issues while reinforcing the importance of finding and using authoritative scientific information.

\section{Acknowledgements}

We would like to acknowledge Carol Montgomery, our Dean of the Libraries and Tracy Hull, our Information Services Department Head for their active encouragement and support of collaborating and allowing events to take place in the Library. We also appreciate Adrienne Hahn from IEEE in assisting us with the events; without her support these events may not have been possible.

\section{Bibliography}

1. Kowalenko, K. (May 2001). Pilot program increases student membership at U.S. colleges. The Institute. Retrieved December 1, 2004 from http://www.theinstitute.ieee.org/toc.jsp?isno=05011

2. Newdick, R. (Oct.1994). E4: the Drexel curriculum. Engineering Science and Education Journal, 3(5), pp. 223-228.

3. Scoles, K., \& Bilgutay, N. (1999). ECE 21: A new curriculum in Electrical and Computer Engineering. 29th ASEE/IEEE Frontiers in Education Conference. pp. 12b5-10-12b5-14.

4. Dowell, E., Baum, E., \& McTague, J. (1994)., The Green Report: Engineering Education for a Changing World. Retrieved November 27, 2004 from http://www.asee.org/resources/greenReport.cfm

5. Hu, S. (2003). A wholesome ECE education. IEEE Transactions on Education, 46(4), pp. 444-451.

6. Masi, C. (Sept. 1995). Re-engineering engineering education. IEEE Spectrum, 32(9), pp. 44-47.

7. Splitt, F. (Apr. 2003). The challenge to change: on realizing the new paradigm for engineering education. Journal of Engineering Education, 92(2), pp. 181-187

8. Montgomery, C. (2003). The evolving electronic journal collection at Drexel university. Science \& Technology Libraries, 24(1/2), pp. 173-186.

9. Montgomery, C. (2000). "Fast track" transition to an electronic journal collection: a case study. New Library World, 101(7), pp. 294-303.

10. Feldmann, L., \& Feldmann, J. (2000). Developing information literacy skills in freshmen engineering technology students. $30^{\text {th }}$ ASEE/IEEE Frontiers in Education Conference. Session S2E. pp. S2E/1-S2E/4.

11. Bhatt, J., Fromm, E., \& Manion, M. (2004). Engineering ethics, the Drexel Engineering Curriculum and the library - a collaborative teaching partnership. Proceedings of the 2004 American Society for Engineering Education Annual Conference \& Exposition. Retrieved December 12, 2004 from http://www.asee.org/acPapers/2004-773_Final.pdf 


\section{Biographical Information}

MR. JAY BHATT, MSEE, MLIS is the Information Services Librarian (Engineering) at Drexel University. In 2003 Mr. Bhatt received Drexel University's Harold Myers Distinguished Service Award, presented annually to someone "whose service on one or more occasions has been recognized as truly significant in the life of the University." .He is actively involved with the Engineering Libraries Division of the ASEE.

MR. ANDREW WHEELER is the Information Resources Technician (Engineering) at Drexel University. Mr. Wheeler is currently enrolled in the MS (LIS) program at Drexel's College of Information Science and Technology.

MRS. RUTH WOLFISH, IEEE Customer Relations Manager, provides training for IEEE online products, distributes informational materials to drive usage, answers all usage questions, and performs both on-site and internet conference training. Mrs. Wolfish came to IEEE in 2001 from Lucent Technologies. 